\title{
PHENYLEPHRINE AND PILOCARPINE IN THE TREATMENT OF POST-OPERATIVE IRIDO-CORNEAL ADHESION
}

\author{
HOMAYOUN TABANDEH, GRAHAM M. THOMPSON, CHEE KON and THOMAS BOLTON \\ London
}

\begin{abstract}
SUMMARY
Following cataract surgery, entrapment of the iris within the surgical wound is often managed by intensive use of miotics. As the radial fibres stretch, only a small amount of traction is exerted upon the entrapped iris. Application of a combination of phenylephrine and pilocarpine drops causes simultaneous contraction of the pupil sphincter and the radial muscle fibres. This study investigated the relative magnitude of forces induced in the iris periphery by pilocarpine and phenylephrine and the effectiveness of adding g. phenylephrine $10 \%$ to g. pilocarpine $4 \%$ drops in the treatment of postoperative irido-corneal adhesions. The investigation was divided into two parts. First, the forces induced in the iris periphery upon exposure to pilocarpine and phenylephrine were measured in 6 cadaver irises. The mean force was $27.5 \pm 5.7 \times 10^{-3} \mathrm{~N}$ for pilocarpine and 23.3 $\pm 4.0 \times 10^{-3} \mathrm{~N}$ for phenylephrine. The combination of the two drugs produced a force of $54.2 \pm 6.6 \times$ $10^{-3} \mathbf{N}(p<0.05)$. In the second part of the study intensive pilocarpine $4 \%$ drops were administered to 17 patients who had iris-wound entrapment on the first post-operative day. Patients with persistent adhesion were commenced on intensive g. phenylephrine $10 \%$ and assessed after 90 minutes. Of the 17 patients, 6 responded to pilocarpine drops alone; in a further 7 the irido-corneal adhesion was released only by the addition of phenylephrine drops, and in 4 patients drops were ineffective in relieving the adhesion. This study indicates that addition of phenylephrine $10 \%$ to pilocarpine $4 \%$ drops enhances the effectiveness of pharmacological treatment of post-operative irido-corneal adhesion.
\end{abstract}

Adherence of the iris to the internal opening of the corneal wound or its incarceration within the surgical section is a not uncommon complication of cataract surgery. If untreated, the adhesions may result in

Correspondence to: Homayoun Tabandeh, MRCP, FRCOphth, Department of Ophthalmology, St George's Hospital, London SW17 0QT, UK. Fax: (0181) 7847826. pupillary distortion, synechiae formation, corneal vascularisation and prolonged anterior uveitis with its sequelae. Closure of large parts of the drainage angle gives rise to secondary angle closure glaucoma. Apart from direct surgical intervention, the treatment has included intensive use of pilocarpine eye drops. ${ }^{1}$ It is thought that sphincter contraction will stretch the dilator muscle fibres and hence will pull the incarcerated iris out of the surgical wound. However, due to the elasticity of the radial fibres, the contraction force of the sphincter pupillae is dissipated. Phenylephrine, through its $\alpha$-adrenergic effect, causes contraction of the radial fibres of the iris. A combination of pilocarpine and phenylephrine causes simultaneous contraction of the pupil sphincter and the radial muscle fibres and, theoretically, exerts maximal traction upon the entrapped iris tissue. This study investigated the relative magnitude of forces that are induced in the iris periphery by pilocarpine and phenylephrine and the effectiveness of adding phenylephrine $10 \%$ drops to $g$. pilocarpine $4 \%$ drops in the treatment of post-operative irido-corneal adhesions.

\section{METHODS AND SUBJECTS}

\section{Laboratory Investigations}

The iris and anterior uveal tissue of 6 donor eyes were isolated and stored in Krebs solution at $4{ }^{\circ} \mathrm{C}$ for a maximum period of 48 hours. A fine suture $(10 / 0$ nylon) was passed through the iris periphery at a location corresponding to the site of iris prolapse. The iris tissue was placed in an organ bath containing Krebs solution at $37{ }^{\circ} \mathrm{C}$, gassed with $95 \%$ oxygen and $5 \%$ carbon dioxide in order to maintain the oxygenation and the acid/base balance with a $\mathrm{pH}$ of 7.2 (Fig. 1). A large reservoir supplied fresh solution for washing out of the organ bath. The suture was attached to a Statham pressure transducer (Gould) which was in turn connected to a potentiometric recorder (Kipp and Zonen). A second suture secured 


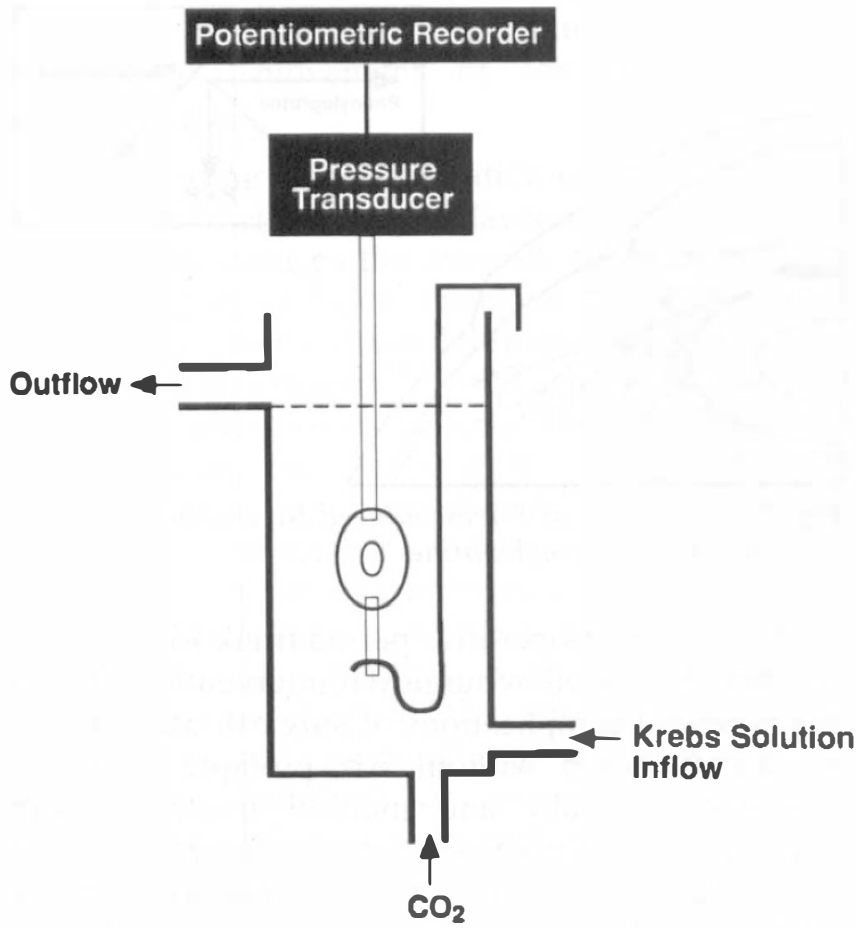

Fig. 1. Organ bath containing Krebs solution at $37^{\circ} \mathrm{C}$ and gassed with $95 \%$ oxygen and $5 \%$ carbon. A fine suture connected the iris periphery to a Statham pressure transducer. A second suture secured the iris inferiorly.

Table I. Grading of post-operative iris entrapment

\begin{tabular}{ll}
\hline I. No irido-corneal adhesion \\
Irido-corneal adhesion to the posterior lip of the wound $\leqslant 1$ \\
clock-hour
\end{tabular}

the iris inferiorly. The recorder was calibrated and once baseline tone was achieved $20 \mu \mathrm{g} / \mathrm{ml}$ of pilocarpine was added to the bath. The presssure trace was recorded and once maximum force was retained for a period of 5 minutes, the organ bath was thoroughly washed out until the muscle tension returned to its baseline value. The procedure was repeated with $50 \mu \mathrm{g} / \mathrm{ml}$ of phenylephrine and then a

Table II. The force induced in the iris periphery following exposure to pilocarpine, phenylephrine and a combination of the two

\begin{tabular}{lccc}
\hline & \multicolumn{3}{c}{ Force $\left(\mathrm{N} \times 10^{-3}\right)$} \\
\cline { 2 - 4 } Iris & $\begin{array}{c}\text { Pilocarpine } \\
20 \mu \mathrm{g} / \mathrm{ml}\end{array}$ & $\begin{array}{c}\text { Phenylephrine } \\
50 \mu \mathrm{g} / \mathrm{ml}\end{array}$ & $\begin{array}{c}\text { Pilocarpine 20 } \mu \mathrm{g} / \mathrm{ml}+ \\
\text { phenylephrine } 50 \mu \mathrm{g} / \mathrm{ml}\end{array}$ \\
\hline 1 & 50 & 40 & 75 \\
2 & 20 & 20 & 40 \\
3 & 20 & 10 & 45 \\
4 & 30 & 25 & 45 \\
5 & 10 & 25 & 45 \\
6 & 35 & 20 & 75 \\
Mean & 27.5 & 23.3 & 54.2 \\
SD & 14.1 & 9.8 & 16.3 \\
SEM & 5.7 & 4.0 & 6.6 \\
\hline
\end{tabular}

Table III. Differences in forces induced by pilocarpine, phenylephrine and their combination

\begin{tabular}{lccc}
\hline & $\begin{array}{c}\text { Mean } \\
\text { difference }\end{array}$ & $\begin{array}{c}95 \% \text { confidence } \\
\text { interval }\end{array}$ & $p$ \\
\hline $\mathrm{F}_{\mathrm{pil}}-\mathrm{F}_{\mathrm{p} \& \mathrm{p}}$ & -26.7 & -43.5 to -9.9 & $<0.05$ \\
$\mathrm{~F}_{\text {phen }}-\mathrm{F}_{\mathrm{p} \& \mathrm{p}}$ & -30.8 & -47.6 to -14.0 & $<0.05$ \\
$\mathrm{~F}_{\text {pil }}-\mathrm{F}_{\text {phen }}$ & +4.2 & -12.6 to +21.0 & $>0.05$ \\
\hline
\end{tabular}

$F_{p i l}$, force induced by pilocarpine; $F_{\text {phen }}$, force induced by phenylephrine; $F_{p \& p}$, force induced by the combination of pilocarpine and phenylephrine.

combination of the two drugs together. These concentrations are supramaximal and comparable to those achieved in aqueous in clinical situations where intensive topical drug therapy is used. ${ }^{2-4}$

\section{Clinical Investigations}

A double-masked, randomised, placebo-controlled trial involving treatment with pilocarpine, phenylephrine, a combination of the two and placebo drops was considered. However, this would have required a large sample. Considering the low incidence of the condition and taking into account the rapidity and duration of action of the agents, a small pilot study was considered appropriate. Patients with iris-wound entrapment on the first day following extracapsular cataract surgery were assessed with regard to the extent of the entrapment. The iris incarceration/ prolapse was graded according to the degree of iris penetration into the wound and the extent of the lesion (Table I). Patients with frank iris prolapse (grade V and VI) or vitreous loss were excluded from the study as pharmacological treatment was considered unsuitable for this group.

Pilocarpine 4\% drops were administered every 15 minutes for 1 hour. The patients were reassessed and the iris adhesion was graded after 90 minutes. The patients with persistent adhesion were commenced on phenylephrine $4 \%$ eye drops every 15 minutes for 1 hour and reassessed 90 minutes later. Successful response was defined as the complete release of the irido-corneal adhesions with a resulting round pupil.

\section{RESULTS}

\section{Laboratory Investigations}

The mean force induced by pilocarpine was $27.5 \pm$ $5.7 \times 10^{-3} \mathrm{~N}$ and that by phenylephrine was $23.3 \pm$

Table IV. Successful response and the grading of the iris entrapment

\begin{tabular}{lcl}
\hline & No. & Grade \\
\hline $\begin{array}{l}\text { Response to pilocarpine alone } \\
\text { Response to addition of }\end{array}$ & 6 & I (4), II (2) \\
$\begin{array}{l}\text { phenylephrine } \\
\text { No response }\end{array}$ & 7 & I (3), II (3), III (1) \\
Total & 4 & II (1), III (2), IV (1) \\
\hline
\end{tabular}

Figures in parentheses indicate frequency.

${ }^{a}$ One subject had an initial release of iris entrapment which recurred within 24 hours. 
$4.0 \times 10^{-3} \mathrm{~N}$. The combination of the two produced a force of $54.2 \pm 6.6 \times 10^{-3} \mathrm{~N}$. Although there is some variation in each drug group, the combination therapy consistently produced a greater force (Table II). Analysis of the data using one-way analysis of variance confirmed a significant difference between the force induced by the combination and the force resulting from the pilocarpine or phenylephrine alone $(p<0.05$ in both cases). There was no difference between the effects of pilocarpine and phenylephrine. In addition there was no significant difference between the summation of the forces produced by the two individual drugs and the force produced by their combination (Table III).

\section{Clinical Investigations}

Over a period of 2 years a total of 17 subjects from three eye departments were included in the study. None had any previous iris abnormality. Seven subjects had grade I, 6 grade II, 3 grade III and 1 had grade IV iris entrapment. Six cases responded successfully to treatment with pilocarpine alone and a further 7 responded to the addition of phenylephrine to the treatment regime. In 4 the combination therapy did not release the incarcerated iris. The subjects who failed to respond to pilocarpine alone tended to have a higher grade of entrapment (Table IV).

All incisions were corneal and were sutured by $10 / 0$ nylon (12 interrupted, 5 continuous bootlace). In 6 cases aqueous leak was present prior to treatment. Two subjects developed aqueous leak after successful treatment. One of these cases had a recurrence of the iris incarceration 1 day after an initially successful response. This case had significant gaping of the wound and aqueous leakage.

\section{DISCUSSION}

Iris prolapse is an uncommon complication of cataract surgery. Its incidence has been reported as ranging from 0 to $1.4 \% .^{5}$ Entrapment of iris within the surgical wound is a more frequent complication. These adhesions result in prolonged anterior uveitis, pupillary distortion and secondary closed angle glaucoma.

There are various processes which may predispose to iris prolapse or entrapment. In pseudophakic eyes superior zonular and capsular dehiscence resulting in vitreous prolapse may displace the iris into the section. Similarly a displaced superior haptic or a posterior chamber lens implant can move the superior iris forwards. Other factors which may be associated with iris prolapse include shallowing of anterior chamber in conditions such as subclinical or frank choroidal haemorrhage or effusion, an atonic iris together with wound leakage and finally trauma. In most cases a number of factors are present.

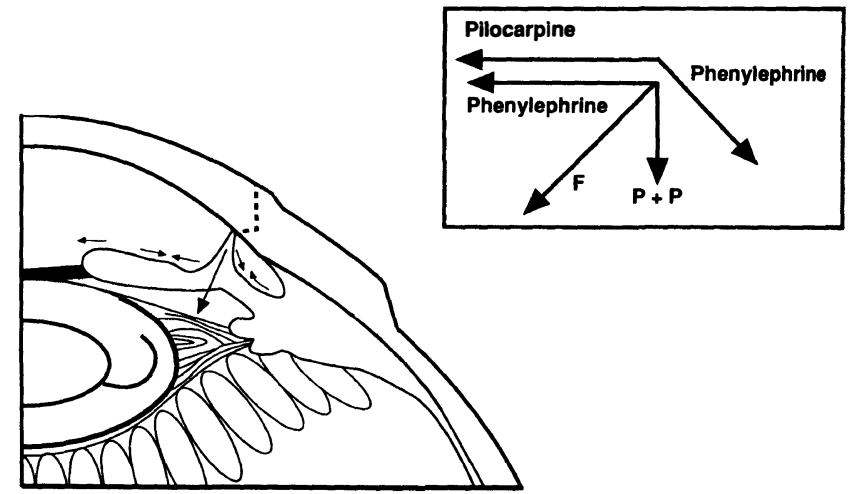

Fig. 2. Direction of forces induced by a combination of pilocarpine and phenylephrine.

In the early post-operative period frank iris prolapse is generally treated by surgical reintervention. Due to the potential complications of surgical intervention, iris incarceration without iris prolapse is rarely managed surgically and medical treatment with intensive topical miotics has been the treatment of choice. However, the use of pilocarpine is not always effective and patients are often left with persistent irido-corneal adhesions resulting in long-term ocular morbidity. Pilocarpine stimulates the muscarinic receptors present on the pupil sphincter muscle fibres, causing sphincter contraction and miosis. In a normal eye pilocarpine penetrates through the cornea producing miosis in 10 minutes. Highest anterior chamber concentration is reached 20 minutes after instillation and miosis is maximal at 30 minutes with a duration of action of 6 hours. ${ }^{2,4,6}$ The aqueous concentration following application of 2 drops of pilocarpine $\mathrm{HCl} 2 \%$ has been shown to be in the region of $5 \mu \mathrm{g} / \mathrm{ml}^{2}$. Phenylephrine stimulates $\alpha_{1}$. receptors within the radial muscle fibres causing mydriasis. Maximal mydriasis from a single instillation occurs within 60 minutes and the effect lasts 6 hours. ${ }^{7-9}$

As the maximal pupil contraction effect of pilocarpine is achieved within 90 minutes and it lasts for 6 hours it can be assumed that in the patients entering the second phase of the study there is simultaneous action of pilocarpine and phenylephrine. In other words in this situation both the sphincter and the radial muscle fibres are contracting (Fig. 2). There is an increased pulling force in the iris periphery as:

1. The force of contraction of pupil sphincter muscle is directly transmitted to the entrapped section of the iris instead of being dissipated by stretching the iris tissue.

2. Contraction of radial muscle fibres by phenylephrine pulls the entrapped section of the iris both centrally and towards the periphery with the net force being directed backwards, generating additional force. 
3. There is deepening of the anterior chamber by backward movement of the 'irido-lenticular' diaphragm. ${ }^{10}$

When using this combination one concern is the induction of closed angle glaucoma. In phakic eyes pilocarpine reduces the anterior chamber depth by increasing pupil block, changing the shape of the lens, as well as by forward displacement of the iridolenticular diaphragm. ${ }^{10-14}$ Phenylephrine does not have any effect on the anterior chamber depth. ${ }^{10}$ In normal eyes, the combination of pilocarpine and phenylephrine has been shown to reduce anterior chamber depth further by increasing pupil block in a mid-dilated pupil. This phenomenon is not observed in eyes which have had iridectomies. In fact in the latter eyes a combination of pilocarpine and phenylephrine deepens the anterior chamber as pupil block and iris bombe are not a feature. ${ }^{10}$ In this respect pseudophakic eyes behave in a similar manner to eyes with iridectomies in the sense that altered lens anatomy prevents the occurrence of pupil block and iris bombe. Therefore induction of acute angle glaucoma is not a real problem.

A combination of muscarinic and adrenergic agents, by tightening the iris structure, may also be useful in the prevention of anterior synechiae formation following procedures such as surgical repair of a lacerated cornea, peripheral iridectomy and holmium laser sclerotomy.

In conclusion, this pilot study demonstrates an increase in the magnitude of forces induced in the iris periphery by a combination of pilocarpine and phenylephrine and suggests that the combination therapy is more effective than pilocarpine alone in the pharmacological treatment of post-operative iris entrapment.

The authors wish to thank Dr Sally Prestwich, Dr Kevin Lawrence, Mr Sean McGuigan and Mr Chad Rostron for their kind assistance.
Key words: Cataract surgery, Iris entrapment, Iris prolapse, Phenylephrine, Pilocarpine.

\section{REFERENCES}

1. Duke Elder S. Prolapse of the iris. In: Diseases of the lens and vitreous. System of ophthalmology, vol. XI. London: Kimpton, 1969:278-9.

2. Krohn DL, Breiter JM. Transcorneal flux of topical pilocarpine to the human aqueous. Am J Ophthalmol 1979;87:50-6.

3. Assef CF, Weisman RL, Podos SM, Becker B. Ocular penetration of pilocarpine in rabbits. Am J Ophthalmol 1973;75:212-5.

4. Chrai SS, Robinson JR. Corneal permeation of topical pilocarpine nitrate in the rabbit. Am J Ophthalmol 1974;74:735-9.

5. Kaushik NC, Morgan LH, Morrison AM. Iris prolapse following cataract surgery. Trans Ophthalmol Soc UK 1983;103:560-1.

6. Thorburn W. The effect of a single dose of pilocarpine on the facility of outflow as estimated by use of a constant pressure technique. Acta Ophthalmol (Copenh) 1974;52:246.

7. Barbee R, Smith WA. A comparative study of mydriatic and cycloplegic agents. Am J Ophthalmol 1957;44:617-22.

8. Haddad NJ, Moyer NJ, Riley FC. Mydriatic effects of phenylephrine hydrochloride. Am J Ophthalmol 1970; 70:729-33.

9. Gambill HD, Ogle KN, Kearns TP. Mydriatic effects of four drugs determined by pupillograph. Arch Ophthalmol 1967;77:740-6.

10. Mapstone R. Closed angle glaucoma in eyes with nonshallow anterior chambers. Trans Ophthalmol Soc UK 1981;101:218-20.

11. Abramson DH, Coleman DJ, Forbes M, Franzen LA. Pilocarpine effect on the anterior chamber and lens thickness. Arch Ophthalmol 1972;87:615-9.

12. Abramson DH, Franzen LA, Coleman DJ. Pilocarpine in the presbyope. Arch Ophthalmol 1973;89:100-2.

13. Gorin G. Angle closure glaucoma induced by miotics. Am J Ophthalmol 1966;62:1063-7.

14. Wilkie J, Drance SM, Schulzer M. The effect of miotics on anterior chamber depth. Am J Ophthalmol 1969; $68: 78-83$. 